\title{
JAMES JOYCE Y ULISES. MODERNIDAD Y PSICOSIS
}

\author{
Sergio Fernández-Miranda López ${ }^{1}$ \\ Hospital de Día de Salud Mental de adultos. Hospital Universitario Torrecárdenas, Almeria
}

El presente trabajo pretende ser una reflexión sobre la importancia capital de la novela "Ulises" y por extensión de su autor, James Joyce, no sólo en la Historia de la Literatura sino como verdadero hito en la construcción del hombre del siglo XX, que justo comenzaba en ese momento. A través de un breve apunte biográfico, análisis del personaje, sus obras y de sus figuras cercanas, se plantea también la relación de éste con el mundo de la psicosis, otro símbolo podría decirse, de ese siglo que se anunciaba.

Palabras clave: James Joyce, Ulises, lenguaje, desorganización, psicosis, esquizofrenia, siglo XX.

This paper pretends to be a reflection on the central importance of the novel "Ulysses" and in extension of its author, James Joyce, not only in the History of Literature but as a real milestone in the construction of twentieth-century man, century which was just beginning at that time. Through a brief biographical note and analysis of the character, his works and his close figures, also poses its relationship with the world of psychosis, another symbol could be said, of this century that was announced.

Key Words: James Joyce, Ulysses, language, disorganization, psychosis, schizophrenia, $X X^{\text {th }}$ century. English Title: James Joyce and Ulysses. Modernity and Psychosis

\section{Cita bibliográfica / Reference citation:}

Fernández-Miranda López, S. (2021). James Joyce y Ulises. Modernidad y Psicosis. Clínica e Investigación Relacional, 15 (1): 216-237. [ISSN 1988-2939] [Recuperado de www.ceir.info ] DOI: 10.21110/19882939.2021.150111

\footnotetext{
1 Psiquiatra y Psicoterapeuta. Hospital de Día de Salud Mental de adultos. Hospital Universitario Torrecárdenas. Contacto:drsergiofernandezmiranda@gmail.com sergiofdezmiranda@hotmail.com. Licenciado en Medicina en Medicina y Cirugía por la Universidad de Granada y especialista en Psiquiatría vía MIR en el Hospital Universitario Torrecárdenas. Terapeuta acreditado por la ISTFP. Máster oficial en Investigación en Salud Mental por la Universidad de Almería y la Universitat Rovira i Virgili de Tarragona. Postgrado Universitario en "Medicina Psicosomática y Psicología de la Salud" por la Universitat Internacional de Catalunya. "Experto en Trastornos de la Personalidad" por la Sociedad Española de Medicina Psicosomática y Psicología Médica Ha realizado estancias formativas en el Centro de Estudios Psicosomáticos de Argentina (con el Dr. Jorge Ulnik), el Instituto de Psicoanalisis Multifamiliar (con el Dr. Garcia-Badaracco) y La Fundación Luis Chiozza y Centro Weizsaecker (con el Dr. Chiozza) en Buenos Aires, Argentina. Formado en Psicoterapia individual psicoanalítica, fenomenológico-existencial y Terapia grupal. Participa en grupos de supervisión de casos. Ha trabajado como Facultativo Especialista de Área en la Unidad de Salud Mental Comunitaria de Almería y en la Unidad de Hospitalización del Hospital Universitario Torrecárdenas. Desde 2015 trabaja en el Hospital de Día de Salud Mental y en el Programa de Intervención Temprana en Psicosis de Almería de dicho Hospital. Ha sido tutor de residentes de psiquiatría del Hospital Universitario Torrecárdenas y responsable del seminario de formación de especialistas desde mayo de 2011 hasta abril de 2020. Es Tutor clínico de la Universidad de Granada. Coordinador y supervisor de la rotación de Entrenamiento en Psicoterapia de la Unidad de Gestión Clínica de Salud Mental de Almería. Docente del Programa de "Medicina Psicosomática" de la "Unidad de Docencia y Psicoterapia José María López Sánchez", del Hospital Universitario Virgen de las Nieves de Granada. Miembro de la International Society of Transference-Focused Psychotherapy (ISTFP). Miembro de la Sociedad Española de Rorschach y métodos proyectivos.
} 
El pasado 13 de enero de 2021 se cumplió el octogésimo aniversario de la muerte de James Joyce. $Y$ si bien su altura literaria ya hubiera justificado más que de sobra tanto una celebración como una reseña, pensamos que merece una reflexión a ciertos aspectos cercanos a nuestro campo de trabajo.

Persona muy compleja, Joyce es difícilmente clasificable. El crítico Harry Levin lo describió como "un irlandés parisino, un hereje católico [...], excomulgado y expatriado, el hombre sin país y sin creencias" (Levin, 2004). Bebedor empedernido y con varias a enfermedades a cuestas, Joyce falleció en Zúrich a los 59 años, a causa de una peritonitis por una úlcera gástrica perforada. Úlcera vieja que fue tratada de "somatización nerviosa" desde siempre, diagnóstico que él abrazó gustoso (López Sánchez, 2003).

Celebramos a Joyce por ser autor de una de las obras más revolucionarias y complejas de la historia de la Literatura, "Ulises", publicada con todas las dificultades del mundo en 1922, hace casi 100 años. "Ulises" se considera uno de los pináculos de la Literatura universal, que trasciende a su lengua inglesa por su singularidad, transformando ambas radicalmente. Su impacto es tal, que su efecto se expande sobre autores y textos de una forma inasumible. Pocos textos pueden presumir de eso. Muy pocos autores y libros se convierten en hitos culturales de semejante manera.

"Ulises" es una revolución formal que trae otra revolución por debajo, no sólo literaria, que toca aspectos culturales, antropológicos, fenomenológicos y sin duda psicopatológicos.

La experiencia de leer a Joyce, leer "Ulises", puede suponer una verdadera lucha, un enfrentamiento. Joyce no es precisamente alguien que escriba buscando una comunicación sencilla y directa con el lector. Relata una historia en constante construcción y deconstrucción a la vez, que se revuelve y se pliega sobre sí misma. Que se llena de autorreferencias, referencias, paralelismos, simbolismos. Que plantea juegos divertidos que nos perdemos en su mayoría los lectores (con cierta intencionalidad al respecto, todo sea dicho). El material se dispone en diferentes planos de complejidad que nos obligan a releer, a repensar, a entrar en una dialéctica con el texto. Anthony Burgess (2000) propone una metáfora muy acertada al respecto de esta experiencia: el Ulises es una de las cumbres de la literatura, desde la que se han despeñado innumerables lectores al intentar escalarla.

Ambos, obra y autor, han adquirido un aire mítico por su complejidad verdadera. De una dificultad tal, real por otra parte, que pareciera que el esfuerzo que precisan no compensara al placer o aprendizaje que pueden aportar. La sombra que proyectan pareciera que empequeñece al lector de a pie que pretenda acercarse a ellos. Muñoz Molina (2004) sobre Beethoven y la Novena Sinfonía dice que lo malo que tienen las obras maestras incontestables es que son a veces como las estatuas de la calle. Llega un momento en que 
uno se acostumbra a su presencia, a su lugar reconocido; $y$ entonces, a fuerza de pasar a su lado, uno deja de mirarlas, olvida que están ahí y deja de interpelarlas, de pararse a escucharlas, a entrar a dialogar con ellas. Esto pasa con "Ulises", libro que intimida desde su mismo principio.

Al avanzar en el texto, poco a poco, releyendo despacio, pensando, se van abriendo diferentes niveles de significación, en una dispersión inimaginable. Bajo cada piedra, cada palabra, surge una referencia, un sonido, un símbolo, que añade color y riqueza. Matices que no es que traigan más, es que directamente es otro libro, mil libros, los que de repente uno va viendo poco a poco en el fondo. La sensación es de un vértigo tal, que es difícil de describir, pero que viene con una profunda fascinación.

La intrincada estructura narrativa de "Ulises" invita a acercarse de otra manera para poder sobrevivir a su lectura. El gobierno del ritmo por encima de todo, lo acerca mucho más de lo esperado a la poesía. Poesía en prosa diríamos, no al estilo del "Ocnos" de Cernuda, pero no tan alejado como pudiera parecer. De hecho, si se lee en inglés en voz alta, a veces pareciera que se canta. Más todavía en el caso del "Finnegans Wake".

La lectura entonces pasa de ser algo lineal, como fantasea nuestra identidad que es su temporalidad, a algo centrífugo, en aparente desestructuración. Y sorprendentemente a su vez es justo lo contrario: la construcción de un edificio inmenso, casi infinito en su complejidad. Borges (1998) defendía entender "Ulises" como una ciudad, a la que se puede entrar desde cualquier sitio, a la que no hay que haberla recorrido entera o sabérsela de memoria para conocerla. Abordarlo como una novela convencional nos pone de frente contra la incomprensión de lo que leemos, por sus propias características. Pero frente a esta vivencia, el juego, la música, el ritmo, nos van envolviendo e invitando a seguir, pese a hacerlo a veces a ciegas.

A propósito de este planteamiento, recordamos a Wilfred Bion, que en "Aprendiendo de la experiencia" (2010) y "Experiencias en grupos" (1996) defiende que la no comprensión de un texto, o de un discurso, no puede llevarnos a abandonarlo, a descartarlo. Hay que dejarse arrastrar por él, entrar en las palabras. Como decía Valéry (2007), que recuperaba José María López Sánchez (2004), "entrar en uno mismo, hasta el final, armado hasta los dientes". Sólo al final, en la Experiencia, se depositan las vivencias que el texto genera, en el juego dialéctico decíamos, que establecemos con él. Y de ese poso viene la comprensión final, que va más allá de un mero entendimiento de lo que nos cuenta la trama, palabra a palabra. 
O en palabras de T.S. Eliot, a propósito de Dante: "Genuine poetry can communicate before it is undestood" (2011).

Eliot, amigo importantísimo para Joyce al inicio, luego no tanto. Y Bion. Podemos ver aparecer varios juegos especulares: Hay un nexo entre Eliot y Bion, quien cita al primero varias veces al reflexionar sobre Pensamiento y Deseo (2010). Eliot, amigo de Joyce, figura importante en las luchas que sufrió por conseguir publicar sus obras. También muy conocida es la línea que va de Joyce a Jung, quien fascinado por el "Ulises" escribió un ensayo elogioso (Jung, 2002) y se ofreció a ser su analista, siendo cortésmente rechazado. Otra de Joyce a su hija Lucía, que trató Jung, completando el triángulo. También de Joyce a Lacan, desde donde la admiración pesaba del lado del francés (y que recibía educados y divertidos desplantes en sus cartas por parte del irlandés) (Zentner, 2008). De James Joyce a Beckett, su asistente. De Beckett a Lucía, enamorada perdidamente de éste, amor no correspondido. $Y$ de Beckett al diván de Bion. Y rizando el rizo aparece una ya tangencial con Anzieu, que dedicó ensayos brillantes a la relación de estos dos últimos (Anzieu, 2013). La vida se entrelaza con la literatura.

Antes de seguir sobre "Ulises" debemos hacer una composición de lugar, entendiendo, si esto es posible, quién fue James Joyce. Porque su figura es tan compleja e indescifrable como su obra. De hecho, pese a su enorme originalidad, hay pocos autores en las que obra y personaje se fundan tanto. Una es continuidad de la otra, no consecuencia. Ni siquiera reflejo.

\section{Un apunte biográfico}

James Joyce nace y crece en la Irlanda que formaba parte del Imperio Británico, siendo descendiente de nacionalistas irlandeses, con los que compartió trato mucho tiempo. Hijo de padre alcohólico, nieto de abuelo alcohólico, incapaces ambos de mantener la economía doméstica obligando a la familia a diferentes trances, heredó él la maldición familiar.

Pero lo más característico de Joyce no fue su relación con el alcohol, larga y por lo que se ve fructífera, sino su relación con la religión católica y con su país natal, fantasmas que lo persiguieron toda su vida.

Explicita Joyce por boca del protagonista de "Retrato de un artista adolescente" (2012): Cuando el alma de un hombre nace en este país, se encuentra con unas redes arrojadas para retenerla, para impedirle la huida. Me estás hablando de nacionalidad, de lengua, de religión. Estas son las redes de las que yo he de procurar escaparme. $\mathrm{Y}$ en eso estuvo todo el tiempo. 
James Joyce tuvo una educación muy católica, matriculándolo sus padres en colegios todos vinculados a la "Orden de Jesús", con el consecuente sacrificio que eso debía acarrear para una familia tan precaria. Precisamente por un desastre económico familiar hubo que cambiarlo de colegio a otro de menor entidad, pero también organizado por jesuitas.

Esta educación fue trascendental en el desarrollo del pensamiento y la sensibilidad del joven Joyce (Vicent, 2009). Por un lado está el obvio acceso a la cultura que de otra forma no hubiera tenido; lecturas exhaustivas de autores clásicos, conocimiento del latín y griego, una fuerte base escolástica. Y de ahí, el desarrollo de un joven lector para sorpresa de sus familiares, que descubre a Flaubert y especialmente a Ibsen, que le transformó el mundo.

En palabras de su hermano Stanislau (de su autobiografía "My brother's Keeper") (2011), que lo acompañó siempre:

Considero poco menos que un milagro que hubiese alguien en mi familia dedicado al cultivo de la poesía o preocupado por mantenerse en contacto con las corrientes del pensamiento europeo, viviendo en una casa como la nuestra, hundida en la miseria de una generación de borrachos. No sé qué fuego interior pudo transfigurarlo.

A la vez en esa educación hay también una impronta más profunda: una forma de ver el mundo le es transmitida al joven estudiante, como lo es para todos nosotros en esas edades. Hablamos de la educación católica ortodoxa previa al Concilio Vaticano Segundo, donde la palabra de Dios es transmitida a través de rituales rigidificados, largas oraciones declamadas en latín, ceremonias cubiertas de un simbolismo casi arcano. No se podía no ya entender, siquiera transmitir el mensaje de Dios si no era de esta forma. Y poco a poco en la fuerza de la repetición, aparece la disolución del mensaje, que pasa a casi desaparecer, quedando la carcasa como el centro del acto.

Esta forma de entender el mundo, de mirar, de pensar, es fuertemente medieval, trasladada a la Filosofía por Tomás de Aquino, a quien tanto cita Joyce en su primera gran obra, "El retrato del artista adolescente". Este pensamiento escolástico da preponderancia a lo formal, a lo estructural, pero con una característica muy particular: El mensaje anida no sólo en el contenido sino también en el continente. Va anudado en la estructura. Por ejemplo, no importa sólo la enseñanza moral que se transmite, sino que esta debe ser bella para ser moral. El arte medieval a su vez está fuertemente influenciado por el pensamiento de Platón, siendo virtud y belleza equivalentes. Porque la forma da sentido a la globalidad. El significado está también entre los fonemas del significante.

Todo esto no cae en el olvido precisamente para Joyce. En "El retrato..." de hecho, es directamente explicitado. Más tarde en "Ulises", y luego hasta el extremo en "Finnewans 
Wake", le dará una vuelta mayor, en ese esfuerzo suyo en transmutar la raíz y lo esencial. Desde el orden rígido de la estructura, desorganizará para reorganizar el lenguaje, añadiendo a los significantes capas y capas de nuevo material.

Volviendo al impacto de esta educación, hay que recordar también cómo eran aquellas instituciones a principios del siglo $X X$. No es de extrañar que aquellos modelos educacionales llevaran al joven Joyce hacia un ateísmo manifiesto. Pero salir de la fe católica no implicó para nada el abandono de cierta fascinación por ese mundo ritualizado, donde todo tiene un sentido, que además viene dado de antemano. En palabras de Levin, subrayadas por Nabokov (2016), Joyce "perdió su religión, pero conservó sus categorías", que no es poca cosa.

Más tarde se matricula en distintas carreras, todas fuera de Irlanda, pero sin ningún tipo de interés práctico al respecto. Ya había publicado pequeños trabajos y tenía muy clara su vocación artística, aunque eso no diera para comer. Intentos de vivir en París, vuelta a Dublín... En esta aparente carencia de proyecto vital, vagabundeando y viviendo de prestado, el mundo cambia el 16 de junio de 1904. Es el día en el que se cruza por la calle con Nora Barnacle, la que será madre de sus dos hijos y su fiel compañera hasta el final, haciendo honor a su apellido ("lapa" o "percebe" en español), en un giro lingüístico de los que tanto le gustaban a Joyce. Nora era una mujer inculta, de un atractivo particular y muy fuerte carácter (Maddoxx, 2016); que no tenía ningún interés en las letras y mucho menos en las que él escribía. Pero compartía con él una visión terrenal y sensual de la vida, con el sexo como eje central del existir, y un rechazo a la moral religiosa asfixiante. Juntos, atados por la misma visión, disfrute lascivo y gozoso de la vida, deciden huir de Irlanda para irse a vivir a Europa. Prácticamente para nunca volver a Dublín, salvo muy contadas y breves ocasiones.

El homenaje definitivo a esta relación tan especial entre estas dos personas perdidas y enamoradas, lo hará Joyce ambientando toda la trama de su "Ulises" en el día de su encuentro, en las calles de su ciudad, quedando el 16 de junio cristalizado para siempre en la historia de la literatura.

Nora no es una espectadora aséptica en la génesis de estas obras maestras. Mujer tan particular, tan paciente, tan sexual y amorosa con él (y a la vez tan fría y poco sostenedora para con sus hijos), ejerce una enorme influencia. Ella está en todos los personajes femeninos que él escribe, como lo está él en los masculinos. Ambos están y a la vez son muchos otros. Y están muchos otros, como es propio de Joyce.

Siempre más o menos bien avenidos, juntos construyeron una familia itinerante por encima de prejuicios y esquemas sociales preconcebidos. Trieste y París puede decirse que 
fueron las dos ciudades donde más tiempo vivieron. Y finalmente Zúrich, huyendo de la ocupación alemana, donde falleció James Joyce.

Entrados en el terreno familiar, sus hijos, especialmente Lucía, merecen unas palabras. Nora estuvo embarazada tres veces y dio a luz a dos hijos vivos, un varón, el primogénito, Giorgio, y dos años más tarde a una niña, Luccia. Ambos nacieron en Trieste, con muchas carencias materiales, cercanos a la pobreza; inmersos en la desorganización máxima habitual del hogar de los Joyce, donde la única fuente de ingresos era lo que obtenía el padre como profesor de inglés o de generosos aportes de terceros. Ambos hijos tenían nombres italianos porque así lo quisieron sus padres, que les hablaban también en italiano, sin que fuera ese el idioma materno de ninguno en esa casa. Nora solía ser mucho más afectuosa hacia su hijo varón. Al igual que en muchas familias, "la niña era para el padre", desde el parecido físico hasta el carácter, pasando por el supuesto genio y las inclinaciones artísticas.

En general en la organización doméstica, era Nora la que imponía límites y castigos; también físicos. James Joyce, en esa línea anárquica y desordenada suya, huyendo del recuerdo de las propias experiencias de infancia, pensaba que debía ser desde el amor y sólo el amor el que enseñara a los niños. Eso sí, amor incongruente, inconsistente e intermitente, siempre y cuando sus escritos, sus enfermedades y sus borracheras lo permitieran.

Los dos hijos intentaron una carrera artística: Giorgio en el Belle Canto, sin ningún resultado, y Luccia en la danza, donde según la fuente que se consulte tenía más o menos futuro. Tristemente, ninguno desarrolló una actividad creativa como medio de vida.

El caso de Lucía es de sobra conocido. Tímida, estrábica, sensible... Diagnosticada de Esquizofrenia, la enfermedad de Lucía marcó profundamente, como es natural, el devenir de su familia. No está claro el inicio de la misma. Unas fuentes hablan del rechazo de Samuel Beckett a sus proposiciones amorosas (Loeb Shloss, 2005). Beckett, asistente de su padre y asiduo en esa casa, siempre fue amigable y cortés con ella pero no quería nada más, cosa que afectó mucho a la frágil Lucía. Otras fuentes señalan como el estresor principal el desinterés de sus padres por su carrera de bailarina moderna (Talbot, 2012). Algo que a ella la entusiasmaba, pero que no importó lo más mínimo; interrumpieron sus clases de danza con una importante personalidad de la época,abruptamente, sin miramientos ni previo aviso a nadie, por cuestiones económicas. Fuera como fuera, Lucía fue rompiéndose poco a poco. Su padre percibía esto de otra manera, como la expresión del genio que ella llevaba dentro, igual que el suyo. 
James Joyce nunca aceptó la enfermedad de su hija. "The wonder wild", como él la llamaba, era una mente privilegiada, una clarividente. Esto lo decía en el sentido literal, lo cual habla también del equilibrio psíquico del padre. Nora, que dicen era víctima de agresiones por parte de su hija Lucía, insistía en que la joven debía ser hospitalizada. Joyce se oponía a esto continuamente. En estas vueltas que da la vida, Jung, del que ya hemos comentado antes cuál fue su contacto previo con Joyce, apenas 2 años después era el especialista de renombre al que ellos consultaron. Fue el psiquiatra de Lucía durante un tiempo, hasta que sus padres no pudieron contener más el rechazo que éste le generaba. Lucía no fue internada hasta 1936, a los 28 años. No volvería a vivir fuera de un hospital psiquiátrico hasta su muerte, en 1982. Siempre recibió cartas amorosas de su padre, de algunas amigas de hospitalizaciones y de Beckett, que fue un fiel amigo hasta el final.

Con esas cartas, hoy casi todas perdidas, escritas suponemos entre neologismos y dobles sentidos, Joyce se esforzaba en demostrar que su hija no estaba loca. Todo lo contrario, que estaba bien cuerda y que era un genio; que transitaba por las mismas cuestiones y preocupaciones que él, que escribía lo mismo que él. Fue ahí cuando recibió la famosa y magistral contestación de Jung, metáfora definitiva del pensamiento esquizofrénico y la vivencia psicótica: "Cierto. (Los dos nadan en el mismo río). Pero allí donde usted sabe nadar y bucea, ella se hunde irremediablemente" (Loeb Shloss, 2005).

No son pocos los que defienden la influencia de Lucía en la escritura del "Finnegans Wake" (Del Conde, 2013). Texto incomprensible, lleno de palabras de nuevo cuño, de asociaciones laxas por asonancia, de música y de símbolos, que empezó a escribir Joyce cuando su hija tenía 17 años y tardó años en terminar. Los hay que hasta defienden una escritura a 4 manos. Hasta a 6 manos si metemos a Beckett. Teorías de la conspiración hay para todos los gustos.

Independientemente de la triste historia de Lucía, traer aquí la esquizofrenia, la psicosis, no es gratuito. Es la confirmación de un fracaso, desde cierto punto de vista. Pero también es el extremo último del camino emprendido por Joyce en la desarticulación del lenguaje de sus significantes y símbolos, para la creación de lugares nuevos. Para abrir el espacio lingüístico a toda una nueva experiencia por descubrir, sólo asido a la música y el ritmo, hasta invadir el pensamiento.

\section{Su obra literaria}

El corpus de las obras de James Joyce es fundamentalmente Narrativa, salvo algunas aproximaciones a la poesía y hasta el teatro. Lo que llama la atención, pese a lo diferentes 
que son unas de otras, es la referencia constante hacia su Dublín natal. Exiliado, no hay otro tema que el padre. Padre entendido como patria y como dios, ambos de los que huyó físicamente, pero sobre los que siempre orbitó, y cuyos fantasmas siempre le persiguieron.

Entre sus obras, sus trabajos más destacados, por orden de publicación, son:

- "Dublineses" (Dubliners) de 1914, una colección de cuentos ambientados en la vida cotidiana de Dublín, que en su conjunto suponen una mirada cronológica a la vida humana. El último relato del libro, titulado "Los muertos", es especialmente hondo. Se asume por todos la fuerte carga biográfica de la mayoría de sus pasajes.

- "Retrato del artista adolescente" (título bellamente traducido por Dámaso Alonso del "Portrait of the Artist as a Young Man" original), que pese a que vio la luz en 1916 es una reconstrucción de un trabajo previo de 1905, "Stephen Hero". Se trata de una reflexión sobre el arte y el acto de creación, disfrazado de narración. Su protagonista es Stephen Dedalus, que ya aparecía brevemente en Dublineses. Stephen Dedalus es directamente un seudónimo de Joyce, que en esta obra se refleja así mismo en su juventud más combativa.

Merece un apunte el nombre del seudónimo. Nada en Joyce es casual, sí tremendamente simbólico. "Stephen" alude a San Esteban, primer mártir cristiano y patrón del lugar de unos de sus colegios donde estudió. Más interesante es el Dedalus, de doble simbología. Viene obviamente de Dédalo, el arquitecto del laberinto de Minos, lo que le viene al pelo a Joyce como creador de grandes estructuras intrincadas. $Y$ también el constructor-creador de unas alas para elevarse sobre la moral católica y el nacionalismo asfixiante. Pero esto no acaba aquí; se añade el hecho del hijo muerto, Ícaro, al imitar a su padre. Esto lo añadimos nosotros pensando en Lucía. Cosas de la magia del lenguaje.

- Ulises (Ulysses), publicado en 1922 y la obra central, la obra maestra de Joyce. Más adelante volveremos detenidamente sobre ella.

- Y el jeroglífico final "Finnegans Wake", publicado en 1939, considerado imposible de traducir (pero con versión completa en español finalmente en 2016, heroico esfuerzo del escritor Marcelo Zabaloy. También existen otros proyectos en marcha) . Ni siquiera los críticos se ponen de acuerdo sobre el argumento de la trama. Sí se entiende esta como circular y palindrómica, acabando el libro con una frase sin terminar, que se continua con la primera frase de la primera hoja, que empieza a la mitad. Un día Finnegan, un obrero de clase baja, se cae de una escalera, se golpea en la cabeza y parece que muere. En su velatorio, entre canciones, alcohol y bromas, derraman whisky sobre su cadáver, que lo hace resucitar. Entre tanto, páginas y 
páginas de juegos de palabras, de palabras nuevas directamente, construidas desde todos los idiomas, mediante silogismos, asonancias, la fonética y la música. La identidad de los protagonistas parece transformarse, surgiendo nuevos protagonistas a la mitad de la novela. Historia coral como las que le gustaban a Joyce, todo el libro parece terminar siendo una enorme metáfora de la historia de la humanidad entera.

"El despertar de los Finnegans", también "El velatorio de los Finnegans" o "de Finnegan", o "El amanecer de los Finnegans" (y esta confusión polisémica sólo en el título), es el reverso de "Ulises" y a su vez su extremo. El reverso porque cuando el "Ulises" todo se desarrolla en el día, el "Wake" lo hace en la noche. "La noche oscura" que diría San Juan de la Cruz. Y pretendidamente esto viene a tener su reflejo en su estilo de escritura, decididamente confuso, onírico. Los personajes, los lugares, hasta la voz dominante, cambian de un momento para el otro, se confunden, se fusionan, dominando por encima de todo la musicalidad del global.

Analizar el "Wake" se toma libros enteros. Sí parece claro que es el radical final del camino que se alcanzaría desarrollando los hallazgos formales de "Ulises". Nadie más lo ha transitado con éxito.

Aquí surge una reflexión en relación con la Espacialidad y la Temporalidad. Ambas estructuras básicas, existenciarios del ser-en-el-mundo, son los ejes sobre los que se asienta el self y aportan equilibrio al aparato mental, en un juego de fuerzas. La Temporalidad vendrá a dar continuidad narrativa a la identidad, que se despliega en el tiempo; la Espacialidad, sostén y asentamiento. Hay mucho escrito sobre cuál es más básica o más imprescindible para la salud del psiquismo, pero intuitivamente la temporalidad se sitúa como referente central. No es casual que haya más patología mental entre la población sorda que entre los ciegos. De alguna manera el oído, al final el lenguaje y el ritmo, aportan una mayor organización al psiquismo.

Joyce exploró, pareciera que de forma deliberada, todo esto. En "Ulises" y especialmente en "Finnegans Wake" (que escribió casi ciego, lo que parece pertinente apuntar), las descripciones espaciales de los lugares son pobres, confusas. Esto desorienta al lector, pero una vez que se entra en la maraña de palabras, el espacio deja de tener ese sentido orientador y se hace menos imprescindible. La conciencia se construye "en al aire" diríamos; no hay un Yo-corporal, un Yo-piel definidos, quedando esta como un líquido, río, sin forma. Y si bien esto debiera sostenerse de alguna manera, Joyce no parece necesitarlo. 


\section{Sobre Ulises}

Merece la pena pararse a pensar en los hallazgos del "Ulises" y algunas de sus ramificaciones.

"Ulises", como es sabido, es la historia de un solo día, un día cualquiera, en la vida de varios personajes, entre los que se erige Leopold Bloom como su protagonista definitivo. Leopold es un hombre judío, sencillo y mediocre, que está casado con una mujer voluptuosa, Molly, otro de los personajes determinantes, que él sabe le es infiel. La novela lo acompaña entre sus quehaceres del día, entre las que surge acompañar para cuidar y proteger a un tercero, otra vez el joven Stephen Dedalus, artista culto y contestatario, con el que siente de repente un vínculo paterno-filial. Con él establece una relación especular particular, que construye desde el sentimiento de pérdida de su único hijo varón, muerto a los pocos días de nacer. Ambos sufren varias aventuras y encontronazos, hasta que finalmente, de madrugada, Leopold vuelve a casa, a la cama con su mujer.

El título es una analogía, tal vez algo forzada pero muy ingeniosa, que remite a la Odisea de Homero, siguiendo a nuestro héroe hasta su vuelta a Ítaca, su dormitorio. Este es un paralelismo forzado, siendo una de las bromas de Joyce, que consideraba su libro al final como un libro de humor, de lo que en verdad tiene mucho. Fue él mismo quien dio en secreto esta clave interpretativa de la novela a sus amigos, una vez publicada, sin pensar que fuera a hacerse nunca pública. Cada capítulo hace referencia, la mayoría de forma muy distante o simbólica, a su capítulo correspondiente de la Odisea de Homero.

¿Por qué la "Odisea"? Porque la "Odisea" es el texto épico por antonomasia, donde el hombre se enfrenta a los dioses y dobla la voluntad de estos a la suya, siendo la definición última de héroe: el humilde ser humano que se sobrepone a todas las dificultades del mundo, sólo armado de su voluntad y dignidad, hasta su meta final.

Y aquí viene una de las grandezas de "Ulises" por encima de sus pericias técnicas, que lo mejor es que están para subrayar el mensaje de fondo: el de constituir al hombre común en un héroe que sobrevive y al final vence en la lucha más difícil, la vida. Que la heroicidad, lo mítico, anida en lo cotidiano, en la vulgaridad de la normalidad y la rutina. Y en la subjetividad.

Para ello Joyce se vale de una serie de recursos tremendamente originales. El más famoso, el más rompedor, fue el que en castellano llamamos "monólogo interior", aunque casi es más apropiado el concepto "flujo de conciencia" que usan en inglés. Consiste en conseguir reflejar a través del texto el libre discurrir de los pensamientos del individuo, sin cortapisas y de la forma más objetiva posible. La proeza de Joyce reside en superar lo que sería 
precisamente un monólogo, la exposición ordenada de un discurso individual interno. Lo que hace Joyce es algo más, es plasmar directamente el proceso del pensamiento, el eco del mismo en nuestro interior. $\mathrm{Y}$ el pensamiento, como ya venía diciendo Freud contemporáneamente (2012), no es para nada un discurso bien armado. Es una producción constante, que se pliega sobre sí misma y se prolonga hacia adelante y hacia atrás. Que es interrumpido por estímulos, por recuerdos, por sonidos, que a la vez regurgita y digiere una y otra vez. Que a la vez vuelve a una serie de temas para deformarlos y convertirlos en otra cosa. Eso sería el pensar, la producción sin forma, gobernada por una serie de temas. Es interesante plantearse la conexión entre el flujo de conciencia con la asociación libre, más cercanas de lo que pudiera pensarse inicialmente, como señala el profesor José María López Sánchez.

La obsesión de Joyce por plasmar apropiadamente este discurrir del pensamiento, lo lleva a otro hallazgo técnico. Ambientado como está el "Ulises" en toda una jornada, conforme se apaga el día y llega la noche, el pensamiento se va desorganizando aún más, como entrando en un estado crepuscular, poco a poco más confuso.

Para poder jugar en este aparente desorden es necesaria, como hemos visto, una estructura externa que contenga, facilite y de un marco para esa producción informe. Esto lo sabe Joyce y se sirve entonces de la Odisea como sostén. La Odisea, referencia, punto de partida de la literatura de Occidente, para transformar Occidente. Partir de la cultura clásica para crear un mundo nuevo.

Se sirve también de otro juego genial: cada capítulo esté escrito en un estilo literario diferente, reflejando, deformando géneros para reírse de ellos y a la vez homenajearlos. Y por si fuera poco añade otro más: cada capítulo hace referencia y simboliza una parte del cuerpo, completando así el libro una metáfora terrenal del ser humano. Demasiadas cosas.

Este armazón, este tour de force técnico, gratuito pero magistral, viene a ser otro asidero más sobre el que empezar la deconstrucción del lenguaje a través otra vez, del ritmo y de la música. "Ulises" es más sinfónico que narrativo. Porque más allá de una historia, somos ritmo. La vida son pautas que se repiten, no otra cosa que ritmos, armonía. Orden cíclico que lucha por sostenerse en el desorden, en la entropía, y a la inversa. Continente y contenido. Otra vez Bion.

Este juego entre la estructura y el contenido le permite hacer su última broma final al pensamiento escolástico y medieval. Además reconocido. Según José María Valverde, autor de probablemente la mejor traducción al castellano del "Ulises", Joyce declaró deber siempre a sus educadores jesuitas el entrenamiento en reunir un material, ordenarlo y presentarlo. Dice Valverde: "No sería arbitrario decir que la obra joyceana es la gran 
contribución -involuntaria, y aun como un tiro salido por la culata-de la Compañía de Jesús a la literatura universal" (2011). De hecho Umberto Eco recuerda que el tipo de confesión jesuítica de entonces y que Joyce aprendió y practicó sin duda, sería un antecedente claro al monólogo interior (Eco, 2011).

A partir de la época de Ulises, el escritor manifestará una postura fríamente neutral frente al hecho religioso, que únicamente le interesaba a efectos lingüísticos. Distinguía, eso sí, el «absurdo coherente» católico del «absurdo incoherente» protestante... (Valverde, 2011)

"Ulises" pretende ser la novela definitiva. En palabras de Edmund Wilson, es "la novela más escrita desde Flaubert" (2001). En ese aparente desorden, el grado de planificación es máximo. Sabemos de la obsesión de Joyce, muy lejos de lo normal, por los detalles más nimios de la vida cotidiana dublinesa, que pretende mostrar desde la prolijidad más radical ( $Y$ eso que ya no vivía allí. Acosaba constantemente a amigos y conocidos a preguntas insufribles). Expone así una mezcla a priori imposible: aunar el Naturalismo y el Simbolismo, todo ello riéndose de su propia madre. $Y$ en alta literatura. Porque en Joyce están Homero, Dante Alighieri, Tomás de Aquino, William Shakespeare, Cervantes, Dujardin, Henrik Ibsen, Flaubert, Giordano Bruno, Giambattista Vico, John Henry Newman, y muchos más.

Entre los símbolos de los que está lleno "Ulises", los ataques al Padre, Irlanda y Catolicismo, son explícitos y de gran riqueza. Porque le parece que el individuo está por encima de esas supuestas grandes cuestiones. Encontramos así verdaderas semillas del futuro Existencialismo. Su forma de atacar la moral es defender la mundanidad y la vulgaridad de la vida. Y que en ella anida el arte. Buscando intencionalmente ser provocador, sonrojar al lector, agitar la moral bien-pensante, se detiene en lo más vulgar, que está en lo más íntimo, para desde ahí, explorar cuánto de arte puede alcanzarse.

El ejemplo paradigmático es el final del capítulo 4, en el que Leopold va al baño a defecar. Allí, mientras piensa, lee y caga, todo va pasando a la vez y se retroalimenta. Las palabras al ser leídas y pensadas, empiezan a intentar transmitir un ritmo intestinal, sincopado, con borborigmos, con una música particular. $Y$ entonces el flujo del pensamiento adquiere ese ritmo hasta el final del acto, reflejándolo en la prosa. Y sorprendentemente con belleza literaria.

Las cotas que se alcanzan en el manejo y uso del lenguaje y la lengua inglesa son impensables. Eso está dicho en muchos sitios, reconocido por todos. Pero entre esos padres simbólicos que se atacan, Patria y Dios, hay otro también, a una madre mejor, la propia lengua inglesa. Esa lengua materna, que lo protegía según él de la necedad del nacionalismo irlandés, y que es la herramienta última en la constitución del aparato mental, 
en sus manos es un juguete que deforma y usa a su antojo para seguir creando y elaborando. Algo que habla de su absoluta genialidad, pero también supone un juego peligroso, una suerte de ruleta rusa: un terreno nuevo en el que entrar, que exige inevitablemente un precio. Porque es al final en el lenguaje donde se sostiene al fondo el pensamiento, y sobre ambos, la vivencia de identidad. No hace falta explicitar cuánto se acerca esa lucha con uno mismo, y el ataque a los vínculos, a ciertas partes psicóticas de la personalidad.

Aquí enganchamos con las reflexiones de Jung con respecto al "Ulises" (1992), diciendo que éste supone al final una destrucción para crear otro algo, pero destrucción al fin y al cabo: "("Ulises" es) un ejercicio espiritual, una disciplina estética, un ritual agonizante, un procedimiento arcano, 18 alambiques alquímicos (por sus 18 capítulos) apilados uno encima del otro [...]. Un mundo se ha desvanecido y se ha vuelto nuevo. [...]"

"Para vivir y soportar la expresión de la destrucción de la personalidad en su creación artística, el artista moderno encuentra justamente en lo destructivo la unidad de su persona artística..."

Y esto escrito dos años antes de tratar a Lucía.

Merece la pena rescatar la carta que le mandó Jung a Joyce tras leer el libro, para presentarle su ensayo al respecto (Brown, 2011), que nos refleja a todos:

Querido señor,

Su "Ulises" le ha presentado al mundo un problema psicológico tan pesaroso que he sido llamado repetidamente como una supuesta autoridad en materias psicológicas.

"Ulises" probó ser una nuez excesivamente dura de roer y ha forzado a mi mente no sólo a los esfuerzos más inusuales, sino también a peregrinaciones más bien extravagantes (hablando desde el punto de vista de un científico). Su libro como un todo no me ha dado descanso de dificultades y lo estuve revisando por tres años hasta que logré sumergirme en él. Pero debo decirle que le estoy profundamente agradecido a usted, al igual que a su gigante opus, porque aprendí muchísimo de él. Seguramente nunca estaré muy seguro si lo disfruté, porque significó demasiado estrujamiento de nervios y de materia gris. Tampoco sé si usted disfrutará lo que yo he escrito acerca del "Ulises" porque no pude evitar decirle al mundo cuánto me aburrió, cuánto refunfuñé, cómo maldije y cómo admiré. Las 40 páginas de texto corrido del final es un hilo de verdaderos duraznos psicológicos (...).

Bien, sólo trato de recomendar a usted mi pequeño ensayo, como un intento divertido de un perfecto extraño que perdió su rumbo en el laberinto de su "Ulises" y por pura buena suerte 
logró salir de él. En todo caso, en mi ensayo usted podrá darse cuenta de lo que "Ulises" le hizo a un psicólogo supuestamente equilibrado.

Con la expresión de mi agradecimiento más profundo, quedo, querido Señor,

Sinceramente suyo,

C. G. Jung.

Umberto Eco, en el magistral análisis "Las poéticas de Joyce" (2011) , a propósito de todo esto apunta: "Jung (en aquella afirmación sobre la destrucción y sobre la esquizofrenia-río donde hundirse) se daba cuenta de que la esquizofrenia adquiría el valor de una referencia analógica y había que considerarla como una especie de operación "cubista" en la que Joyce, como todo el arte moderno, disolvía la imagen de la realidad en un cuadro ilimitadamente complejo, cuyo tono lo daba la melancolía de la objetividad abstracta. Pero en esta operación [...] el escritor no destruye la propia personalidad, como hace el esquizofrénico: encuentra y funda la unidad de su personalidad destruyendo otra cosa. Y esta otra cosa es la imagen clásica del mundo».

Y aquí es donde volvemos a la metáfora de la psicosis. La acertada reflexión de Eco plantea el paralelismo entre la psicosis y la literatura de Joyce, señalando el ejercicio consciente, desde un marco de referencia, de destrucción de un mundo para la construcción de otro. Jung sí subraya que el motor que empuja este impulso destructivo en el psicótico es una profunda necesidad de un sentido, en un universo que se desmorona. Equipara abiertamente la experiencia psicótica, que incluye la elaboración del delirio compensatorio al vacío, con el proceso creador del "artista moderno". Donde el delirio en el psicótico es el dique de contención, en ese "artista moderno" será la obra la que ejerza esa función. Y no se ve en ningún lugar más claro esto que en "Ulises". Mientras que desestructura el lenguaje, demoliendo de paso la novela clásica, Joyce cuestiona, a la vez que celebra, la nueva subjetividad del sujeto.

\section{Ulises, Modernidad y Psicosis.}

Tanto desde el punto de vista literario como histórico, "Ulises" es una obra profundamente moderna. Pese a que Joyce gustaba de marcar distancias con el movimiento modernista (Eco, 2011), se pueden encontrar nexos sin mucha dificultad con los paradigmas del movimiento, en especial en su escuela inglesa. De hecho su originalidad y experimentación por sí solas lo colocan a la vanguardia del movimiento (Sultan, 1990. Orr, 1987). 
Aunque intuitivamente identifiquemos "Modernismo" con Modernidad, este movimiento artístico se enmarca entre las últimas décadas del siglo XIX y las primeras del XX. En cambio, la Modernidad es un periodo histórico que en consenso se extiende desde el XVII aproximadamente hasta bien avanzado el siglo XX. Excesivamente amplio tal vez. Sí podemos afirmar que los cambios sociales y antropológicos que trajo la era moderna llegan a su máxima expresión artística en ese movimiento modernista.

La Modernidad trajo, entre muchos cambios, el dominio de la razón por encima de todo; el pensamiento lógico-racional como forma de entender el mundo. A Descartes debemos la fractura entre el pensamiento, que quedará ligado indefectiblemente ya a la vivencia de existir, y lo material (entre ello el cuerpo, con el impacto consecuente en el enfermar). Esta disociación es hoy llevada hasta el extremo, marcando entonces la existencia separada de un yo pensante omnisciente, trascendente, "objetivo", con el mundo de los objetos, que incluirá por supuesto un yo-cuerpo, objeto, sin duda alguna menor.

Con el desarrollo del pensamiento científico y la atomización del logos, pasamos de una verdad moral, propia del hombre antiguo, a una verdad lógica. Así, la Ciencia pasa a ocupar el lugar de referencia que antes ocupaba la religión. Esa sociedad moderna es aquella de la que hablaba Nietzsche y anunciaba Kierkegaard. Aquella en la que los elementos "dadores" de sentido externo ya no servían, o directamente habían muerto, abriéndose un tiempo nuevo por construir. Ese tiempo nuevo es, por primera vez en la Historia, construído desde el conocimiento, técnico o científico (Korg, 1980). Con el tiempo, la ciencia entronizada irá vaciándose de la incertidumbre que le era innata (por pura angustia nuestra, más que nada), conviertiéndose en un nuevo "en-sí", absoluto, incontestable. No es que hoy seamos ateos. Nada más lejos. Sencillamente hemos cambiado el objeto idolatrado.

En esa sustitución de la religión como elemento estructurante del nuevo orden occidental, además de en la Ciencia, la Modernidad se apoyará también en otros dos pilares finalmente sobredimensionados: nacionalismo y mercado. Sobre los tres se sostendrá la cultura; los tres cosificarán muy poco a poco, cada vez más, al individuo.

Como consecuencia del establecimiento de este nuevo orden, surge otra característica moderna: el hallazgo de la subjetividad. Subjetividad entendida desde la individualidad, el sentido de privacidad y un espacio íntimo interior. El refugio último del sujeto, donde se siente pensante, donde anida el deseo. Esa subjetividad, huérfana entonces de marcos de referencia, cosificada, aparecerá inherentemente frágil, tendente a la desestructuración. Giddens lo expresa en términos sociológicos: "la vida íntima (...) que se va viendo progresivamente descontextualizada" (2001). 
Estos fenómenos son llevados al extremo, superándose la Modernidad no por un planteamiento nuevo sino por un exceso del mismo. Las tendencias anteriores, en lugar de debilitarse, son radicalizadas, universalizadas. Hablamos de la llamada "Pos-modernidad", "Alta Modernidad", "Modernidad líquida"... Conceptos nuevos, que aluden a lo mismo.

La cuestión que nos ocupa, más que un debate por un término nuevo, es el impacto de los cambios sociales y culturales en el psiquismo, en la frágil construcción del individuo de nuestra época.

El pasado siglo XX (tal vez verdaderamente iniciado en los asesinatos de Whitechapel, primer suceso "moderno" (Moore, 2004) y que ejemplifica de forma paradigmática la violencia, los miedos y mecanismos de una sociedad por venir), lo que llevamos del XXI, han traído más soledad, violencia y alienación de la que cabía esperar.

"Ulises", ya en 1922, en su cuestionamiento del mundo desde lo íntimo, atacaba con fiereza los pilares antes mencionados (por supuesto incluyendo la religión), en un acto de emancipación del individuo. Ese intento queda con un poso de melancólica frustración. "Ulises" está preñada de pérdida de sentido, de crisis identitaria (la de Leopold, la de Dedalus, la de Molly...), de fracasos vitales. Angustia, búsqueda y ausencia. Sus protagonistas andan perdidos, huyendo de la soledad, cuestionándose a sí mismos, a través de una mirada irónica hacia el mundo, para finalmente aceptarse con resignación.

Poniendo en perspectiva todo lo dicho, es por lo que debemos entender "Ulises", más que ninguna otra obra, como el culmen literario de aquella Modernidad, y un verdadero pistoletazo de salida, carta de naturaleza, a las angustias de ese siglo $X X$ que recien comenzaba. La subjetividad por encima ya del propio raciocinio, puesta en el centro del pensamiento y la existencia.

Leopold Bloom se nos muestra como el primer hombre verdaderamente moderno (a un paso casi del posmoderno): el sujeto sencillo, atrapado en sus vínculos, sus fantasías, conflictos y angustias, que pasan a ser el centro del mundo. Las pequeñas y sucias cosas que nos rodean, que es lo que al final verdaderamente existe para nosotros.

Este trance tan íntimo que habitamos, hijo de su tiempo, se encuentra cercano a la experiencia psicótica. Tanto más cuando esta es sostenida precisamente por estas vivencias modernas.

Gente de paradigmas tan diferentes como Marino Pérez-Álvarez o José María Álvarez y Fernando Colina, defienden entender el concepto que hoy llamamos "esquizofrenia" como una enfermedad moderna: hija de un siglo XX donde el sujeto anda perdido, con sus 
asideros morales en crisis constante; donde las identidades se construyen en lucha contra algo y no en forma natural y orgánica, y andan siempre en cuestión.

Para Álvarez y Colina (2011), la clave anida en un cambio en la relación entre el individuo y la realidad, entiéndase el lenguaje, llegando finalmente al fracaso de lo simbólico, razón última de la ruptura psicótica. Jáuregui y Méndez (2009) plantean que el delirio viene a representar "el vestigio de la antigua trascendencia", un nuevo elemento estructurador, frente al ataque vivido por los tres centrales (ciencia, nacionalismo, capitalismo). Aquella "pérdida de la evidencia natural" de Blankenburg (2014) parece entonces la consecuencia de una fractura, precisamente en la relación con el impuesto orden natural moderno.

Pérez-Álvarez (2012) subraya la "particular configuración del yo" en ese contexto de separación entre omnipotencia y cosificación, entre interior y exterior. Señala también el papel jugado por el desarrollo tecnológico, que refuerza la vivencia de extrañeza sobre el funcionamiento del mundo, favoreciendo una reificación de la experiencia subjetiva del sujeto.

Sin duda todos estos factores se hilvanan y se desarollan en inter-relación. Como expresa Stanghellini, es legítimo pensar que este dualismo radical entre un sujeto que es pensamiento y un objeto que es concebido en su pura y simple externalidad extensa (pura conciencia y pura materialidad) es el eidos fundamental tanto de la modernidad como de la despersonalización esquizofrénica» (2004).

$Y$ en ese dualismo radical, al borde del precipicio, danza el lenguaje. El ejercicio "esquizofrénico" que hace Joyce sobre el lenguaje, que como hemos señalado se sostiene sobre las sólidas bases de la cultura clásica, tiene mucho de anuncio de los conflictos existenciales que estaban por venir. Enraíza con las dificultades entonces nuevas y ahora llevadas a su máxima expresión, en el devenir de los procesos de maduración, estructuración y asentamiento del self. No hablamos ya sólo de literatura. Hablamos de la inauguración del Hombre en la Pos-modernidad; tan pequeño, tan insignificante, y a la vez $\tan$ heroico.

A la lectura de "Ulises" que lo fascinó, su por entonces todavía amigo, el poeta Eliot, sólo encontraba una pega, esgrimida en un verso: "la especie humana no puede soportar mucha realidad" (2006). No parece descabellada. Parece una última broma irónica del bueno de Joyce, llevar el conflicto hasta el extremo; gestando en el proceso, con todo el sufrimiento, a una ilustre y mágica esquizofrénica en su hija, y un libro a la par. Hermoso y terrible. 


\section{Final}

James Joyce es junto con Proust y Kafka, los verdaderos renovadores de la literatura de principios de siglo XX. Gigantes que abrieron la puerta hacia terrenos inexplorados en los que todavía seguimos perdidos, de alguna manera.

Si aquellos "maestros de la sospecha", Marx, Nietzsche y Freud, nos invitaron a pensar en las zonas oscuras que decididamente buscábamos esconder, ocultar y negar, estos tres escritores directamente nos empujaron a esos lugares; donde frente a la angustia, la melancolía, la miseria, la soledad, la memoria, la lujuria y al final la vida, sólo tenemos palabras, que demasiado fácilmente se quedan cortas.

Ante esa nada, donde el lenguaje parece no llegar, debemos mantenernos firmes y serenos. Porque siempre hay herramientas. Porque en eso consiste estar vivo.

Terminamos con dos citas. Terminamos entonces sólo como se puede, con poesía. Primero con un poema de Borges dedicado a Joyce (2013):

En un día del hombre están los días

del tiempo, desde aquel inconcebible

día inicial del tiempo, en que un terrible

Dios prefijó los días y agonías

hasta aquel otro en que el ubicuo río

del tiempo terrenal torne a su fuente,

que es lo Eterno, y se apague en el presente,

el futuro, el ayer, lo que ahora es mío.

Entre el alba y la noche está la historia

universal: Desde la noche veo

a mis pies los caminos del hebreo,

Cartago aniquilada, Infierno y Gloria.

Dame, Señor, coraje y alegría

para escalar la cumbre de este día.

Cambridge, 1968

"Elogio de la sombra" 
Y finalmente con las palabras de Stephen Dedalus, en el capítulo 9 de "Ulises", mientras discute sobre Hamlet y sobre la vida (Joyce, 2013):

Every life is in many days, day after day. We walk through ourselves, meeting robbers, ghosts, giants, old men, young men, wives, widows, brothers-in-love. But always meeting ourselves.

Toda vida consiste en muchos días, día tras día. Caminamos a través de nosotros mismos, encontrando ladrones, fantasmas, gigantes, viejos, jóvenes, esposas, viudas, cuñados adulterinos. Pero siempre encontrándonos a nosotros mismos.

\section{REFERENCIAS}

Álvarez, J.M. y Colina, F. (2011). Origen histórico de la esquizofrenia e historia de la subjetividad. Frenia, $X I, 7-26$.

Anzieu, D. (2013). Crear Destruir. Madrid: Biblioteca Nueva. (Orig. 1996).

Bion, WR. (1962). Aprendiendo de la experiencia. Buenos Aires: Paidos. (Orig. 1975).

Bion, WR. (1996). Experiencias en grupos. Buenos Aires: Paidos. (Orig. 1961).

Bion, W.R. (2010). Transformaciones. Valencia: Promolibro. (Orig. 1965).

Blankenburg, W. (2014). La Perdida De La Evidencia Natural. Una Contribucion A La Psicopatologia De La Esquizofrenia. Santiago de Chile: Ediciones Udp. (Orig. 1971).

Borges, J.L. (1998). Textos cautivos. Madrid: Alianza Editorial. (Orig. 1986).

Borges, J.L. (2013). Poesía completa. Barcelona. DeBolsillo.

Brown, R. (2017). A companion to James Joyce. Oxford: Wiley-Blackwell.

Burgess, A. (2000). Re Joyce. New York: W W Norton \& Co Inc.

Del Conde, T. (2013). James y Lucia Joyce, Samuel Beckett, Carl Gustav Jung y el Wake. Anales del Instituto de Investigaciones Estéticas, 35(103), 141-176.

Eco U. (2011). Las poéticas de Joyce. Barcelona: DeBolsillo. (Orig. 1965)

Eliot T.S. (2006). Cuatro cuartetos. Madrid: Cátedra 2006. (Orig. 1945)

Eliot T.S. (2011). Bosque sagrado. Edición bilingüe. Madrid: Cuadernos De Langre S.L. (Orig. 1920)

Ellman R. (2002). James Joyce. Barcelona: Anagrama. 2002. (Orig. 1959)

Freud S. (2012). Psicopatología de la vida cotidiana. Obras completas. Vol. VI, Madrid: Amorrortu. (Orig. 1901). 
Giddens, A. (1995). Modernidad e Identidad del yo. El yo y la sociedad en la época contemporánea. Barcelona: Ediciones Península/ Ideas. (Orig. 1991)

Giddens A. (2001). Habermas y la Modernidad. Madrid: Ediciones Cátedra.

Jáuregui, I. y Méndez, P. (2009). Modernidad y Delirio. Ciencia, Nación y Mercado como escenarios de la locura. Madrid: Ediciones Escalera.

Joyce, J. (2012). Retrato del artista adolescente. Madrid: Alianza. (Orig. 1916)

Joyce, J. (2011). Ulises. Barcelona: DeBolsillo. P345-346. (Orig: 1922)

Joyce, J. (2013). Ulysses. New York: Simon \& Brown. p383. (Orig: 1922)

Joyce, S. (2011). Mi hermano James Joyce Madrid: Adriana Hidalgo Editora España. (Orig: 1958).

Jung, C.G. (2002). Ulises: un monólogo. Obra Completa libro 8 Vol 15. $2^{\text {a }}$ edición. (Orig: 1932)

Jung, C.G. (1992). ¿Quién es Ulises? Buenos Aires: Enrique Santiago Rueda Editor. (Orig: 1932)

Korg, J. (1980). Language in Modern Literature: Innovation and Experiment. Brighton: The Harvester Press.

Levin, H. (2004). James Joyce: Introducción crítica. Madrid: Fondo de Cultura Económica de España. (Orig: 1941).

Loeb Shloss, C. (2005). Lucia Joyce: To Dance in the Wake. London: Bloomsbury Publishing PLC.

López Sánchez, J.M. (2003). Las enfermedades de Joyce. Investigaciones Clínicas; 6 (3) 272-275.

López Sánchez, J.M. (2004). Mirando personas. Granada: Lichtung libro.

Maddoxx, B. (2016). Nora. Barcelona: DeBolsillo. (Orig: 1998)

McCourt, J. (2002). Los años de esplendor: James Joyce en Trieste, 1904-1920. Madrid: Turner. (Orig: 2000).

Moore, A. (2004). From Hell. Barcelona: Planeta deAgostini (Orig:1996)

Muñoz Molina, A. (2004). La marsellesa de la humanidad. Madrid: El País Clásica.

Nabokov, V. (2016). Curso de literatura europea. Barcelona: Ediciones B. (Orig: 1980).

Orr, J. (1987). The making of the Twentieth-century Novel: Lawrence, Joyce, Faulkner and beyond. London: Palgrave Macmillan.

Pérez-Álvarez, M. (2012). Esquizofrenia y cultura moderna: razones de la locura. Psicothema. Vol. 24, $n^{\circ} 1,1-9$.

Sultan, S. (1990). Eliot, Joyce and Company. Oxford: University Press. 
Stanghellini G. (2004). Disembodied spirits and deanimated bodies. The psychopathology of common sense. Oxford: University Press.

Talbot, M. y Talbot, B. (2012). La niña de sus ojos Barcelona: Ediciones La Cúpula. (Orig: 2012)

Valéry, P. (2007). Cuadernos (1894-1945). Barcelona: Galaxia Gutenberg.

Valverde, JM. (2011). Introducción y traducción de "Ulises" de James Joyce. Barcelona: Ed. DeBolsillo.

Vicent, M. (2009). Póquer de ases. Madrid: Alfaguara.

Wilson E. (2001). Ulises de James Joyce. En Benet, J. (Ed.) 2001. Críticas ejemplares. Madrid: Bitzoc. (Orig 1997).

Zentner, O; (2008). La correspondencia Joyce-Lacan. Revista de Psicoanálisis. 65(04), pp. 805-817

Original recibido con fecha: 19/5/2020 Revisado: 15/3/2021 Aceptado: 30/03/2021 